\title{
Filigrane
}

Écoutes psychothérapiques

\section{Oser la rencontre. Foi et psychanalyse, de Cécile Dionne \\ Cécile Dionne, Oser la rencontre. Foi et psychanalyse, Montréal, Médiaspaul, 2011}

\section{Marie-Ange Pongis-Khandjian}

Volume 20, numéro 1, printemps 2011

URI : https://id.erudit.org/iderudit/1004042ar

DOI : https://doi.org/10.7202/1004042ar

Aller au sommaire du numéro

Éditeur(s)

Revue Santé mentale au Québec

ISSN

1192-1412 (imprimé)

1911-4656 (numérique)

Découvrir la revue

Citer ce compte rendu

Pongis-Khandjian, M.-A. (2011). Compte rendu de [Oser la rencontre.

Foi et psychanalyse, de Cécile Dionne / Cécile Dionne, Oser la rencontre. Foi et psychanalyse, Montréal, Médiaspaul, 2011]. Filigrane, 20(1), 83-84.

https://doi.org/10.7202/1004042ar 


\section{Oser la rencontre. Foi et psychanalyse, de Cécile Dionne}

\section{Marie-Ange Pongis-Khandjian}

orsque Cécile Dionne, religieuse ursuline et psychothérapeute psychanalytique, m'a demandé de lire son livre avant publication, j’ai accepté, touchée par la confiance qui m'était témoignée, titillée cependant par un certain malaise. Psychanalyste, catholique romaine autrefois, passée dans le camp des mécréants agnostiques depuis longtemps, sans pour autant renoncer à une certaine forme de spiritualité au sens très large du terme, je craignais le hiatus.

Alors que foi et psychanalyse peuvent paraître incompatibles, dans son livre Oser la rencontre, édité par Médiaspaul en 2011, Cécile Dionne s’interroge sur ce qu'ont en commun ces deux domaines. Dans une approche d'approfondissement et à l'instar de Marie Balmary ${ }^{2}$, Françoise Dolto ${ }^{3}$, Julia Kristeva ${ }^{4}$, Marie Romanens ${ }^{5}$ et d'autres, elle explore la relation que Freud avait avec le judaïsme et se réfère à Ernest Jones qui présente l'obstination de Freud à ne pas croire comme une lutte contre son désir de croire.

Elle retrace l'historique du fossé qui s'est établi au début du $\mathrm{Xx}^{\mathrm{e}}$ siècle entre les tenants de la doctrine freudienne et le monde catholique. Ce dernier craignait que la psychanalyse ne mène vers un pansexualisme effréné alors que pour Freud « [1]e fait de rendre conscientes, [...] les convoitises sexuelles refoulées, rend bien plus possible une maîtrise de celles-ci [...]»

L'auteur creuse, avec rigueur et sensibilité, les similitudes entre ces démarches s'inscrivant toutes deux dans une expérience relationnelle tissée à travers la parole prononcée, entendue, interprétée et basée sur la confiance en l'autre. Elle veut y voir des alliés luttant pour sauvegarder, dans un monde asséchant, un certain humanisme. Elle explore le dialogue possible entre ces deux approches du mystère humain tout en respectant l'identité et l'originalité de chacune sans les fusionner ni les confondre. Elle illustre comment la psychothérapie psychanalytique aide à conquérir son identité, s'éduquer au plaisir en se libérant des fausses culpabilités, acquérir plus de liberté intérieure. Ce chemin d'intériorité et de maturité, cette mise au monde, peut favoriser 
une ouverture au spirituel, introspection psychologique et quête spirituelle pouvant s'enrichir mutuellement.

L'auteur tisse des liens entre ces deux approches caractérisées par le même respect pour la complexité de l'humain et met en évidence une alliance possible favorisant un mouvement d'unification de tout l'être.

Cécile Dionne retrace enfin son parcours personnel avec un langage poétique, des mots simples qui s'adressent au cœur, au corps et à l'âme. Elle témoigne de la façon dont elle a pu conjuguer, en tant que femme, sa double allégeance à la foi chrétienne et à la pensée psychanalytique sans toutefois nier les tensions et les questionnements inhérents à une telle conciliation. Elle dit n'avoir jamais rencontré de carrefours où il lui aurait fallu choisir entre les deux voies.

Oser la rencontre. Foi et psychanalyse est un petit livre quant au nombre de pages, mais grand par l'authenticité de son propos. À une époque où les abus perpétrés par des hommes d'église attirent l'attention, les formateurs de jeunes et moins jeunes souhaitant s'engager dans la vie religieuse auraient tout avantage à le leur faire lire. Il intéressera aussi toute personne ayant le goût de rouvrir un questionnement personnel sur les liens entre introspection et spiritualité.

Marie-Ange Pongis-Khandjian

1180 , av. Murray

Québec G1S 3B6

\section{Notes}

1. Cécile Dionne, Oser la rencontre. Foi et psychanalyse, Montréal, Médiaspaul, 2011

2. M. Balmary, Freud jusqu'à Dieu, Acte Sud, 2010.

3. F. Dolto, L'évangile au risque de la psychanalyse, Éditions du Seuil, 1977.

4. J. Kristeva, Cet incroyable besoin de croire, Bayard, 2007 et Thérèse, mon amour, Fayard 2008.

5. M. Romanens, Le divan et le prie-Dieu, Desclee de Brouwer, 2000. 